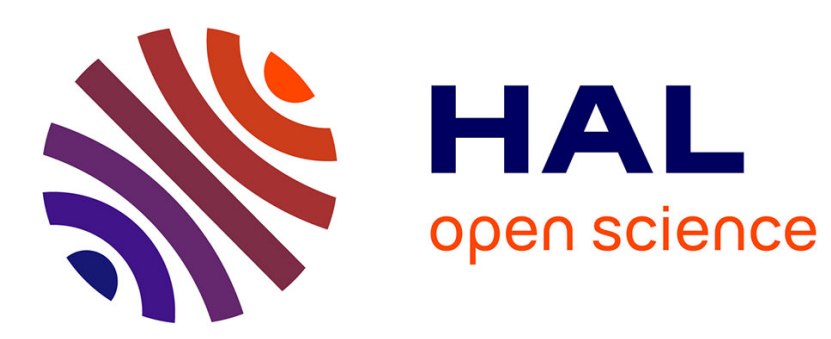

\title{
Implementation and experimental validation of a modeling tool for humid air turbine saturators
}

\author{
Francesco Caratozzolo, Alberto Traverso, Aristide F. Massardo
}

\section{To cite this version:}

Francesco Caratozzolo, Alberto Traverso, Aristide F. Massardo. Implementation and experimental validation of a modeling tool for humid air turbine saturators. Applied Thermal Engineering, 2011, 31 (16), pp.3580. 10.1016/j.applthermaleng.2011.07.022 . hal-00789876

\section{HAL Id: hal-00789876 \\ https://hal.science/hal-00789876}

Submitted on 19 Feb 2013

HAL is a multi-disciplinary open access archive for the deposit and dissemination of scientific research documents, whether they are published or not. The documents may come from teaching and research institutions in France or abroad, or from public or private research centers.
L'archive ouverte pluridisciplinaire HAL, est destinée au dépôt et à la diffusion de documents scientifiques de niveau recherche, publiés ou non, émanant des établissements d'enseignement et de recherche français ou étrangers, des laboratoires publics ou privés. 


\section{Accepted Manuscript}

Title: Implementation and experimental validation of a modeling tool for humid air turbine saturators

Authors: Francesco Caratozzolo, Alberto Traverso, Aristide F. Massardo

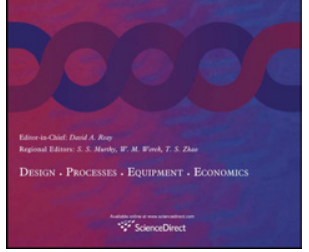

PII:

S1359-4311(11)00381-4

DOI:

10.1016/j.applthermaleng.2011.07.022

Reference: $\quad$ ATE 3649

To appear in: Applied Thermal Engineering

Received Date: 23 September 2010

Revised Date: 11 July 2011

Accepted Date: 14 July 2011

Please cite this article as: F. Caratozzolo, A. Traverso, A.F. Massardo. Implementation and experimental validation of a modeling tool for humid air turbine saturators, Applied Thermal Engineering (2011), doi: 10.1016/j.applthermaleng.2011.07.022

This is a PDF file of an unedited manuscript that has been accepted for publication. As a service to our customers we are providing this early version of the manuscript. The manuscript will undergo copyediting, typesetting, and review of the resulting proof before it is published in its final form. Please note that during the production process errors may be discovered which could affect the content, and all legal disclaimers that apply to the journal pertain. 
Francesco Caratozzolo

francesco.caratozzolo@unige.it

\section{IMPLEMENTATION AND EXPERIMENTAL VALIDATION OF A MODELING TOOL FOR HUMID AIR TURBINE SATURATORS}

Thermochemical Power Group (TPG) - DIMSET, Università di Genova, Genova, Italy

\author{
Alberto Traverso \\ alberto.traverso@unige.it \\ Aristide F. Massardo \\ massardo@unige.it
}

\section{ABSTRACT}

This work presents the re-engineering of the TRANSAT 1.0 code which was developed to perform off-design and transient condition analysis of Saturators and Direct Contact Heat Exchangers. This model, now available in the 2.0 release, was originally implemented in FORTRAN language, has been updated to $C$ language, fully coded into MATLAB/Simulink® environment and validated using the extensive set of data available from the MOSAT project, carried out by the Thermochemical Power Group of the University of Genoa. The rig consists of a fully instrumented modular vertical saturator, which is controlled and monitored with a LABVIEW ${ }^{\circledR}$ computer interface. The simulation software showed fair stability in computation and in response to step variation of the main parameters driving the thermodynamic evolution of the air and water flows. Overall the model proved to be reliable and accurate for energy systems simulations.

\section{NOMENCLATURE}

A

section area $\left[\mathrm{m}^{2}\right]$

$a$ liquid/gas interface area $\left[\mathrm{m}^{2} / \mathrm{m}^{3}\right]$ parameter for eq. (20) $\left[\mathrm{J} /\left(\mathrm{kg} \cdot \mathrm{m} \cdot \mathrm{K}^{2}\right)\right]$ constant pressure specific heat $[\mathrm{J} /(\mathrm{kg} \bullet \mathrm{K})]$ constant volume specific heat $[\mathrm{J} /(\mathrm{kg} \bullet \mathrm{K})]$ infinitesimal saturator cell height [m]

$d \dot{m}_{c}$ condensate mass flow $[\mathrm{kg} / \mathrm{s}]$ enthalpy $[\mathrm{J} /(\mathrm{kg} \cdot \mathrm{K})]$, convective heat transfer coefficient $\left[\mathrm{W} / \mathrm{m}^{2} \mathrm{~K}\right]$ dry enthalpy $\left[\mathrm{J} / \mathrm{kg}_{\mathrm{da}}\right]$ latent heat of vaporization $[\mathrm{J} /(\mathrm{kg} \cdot \mathrm{K})]$ Humid Air Turbine conductive heat transfer coefficient $[\mathrm{W} / \mathrm{m} \bullet \mathrm{K}]$ 


\begin{tabular}{ll}
$k_{x}$ & mass transfer coefficient $\left[\mathrm{kmol} / \mathrm{s} \mathrm{m}^{2}\right]$ \\
in & inlet \\
$L$ & length $[\mathrm{m}]$ \\
$M$ & mass $[\mathrm{kg}]$ \\
$\dot{m}$ & mass flow $[\mathrm{kg} / \mathrm{s}]$ \\
$M O S A T$ & MOdularSATurator \\
out & outlet \\
$o s$ & over-saturation \\
$p$ & pressure $[$ Pa] \\
$q$ & heat flux $[\mathrm{kW}]$ \\
$r$ & radius [m] \\
$R$ & thermal resistance $[\mathrm{K} / \mathrm{W}]$ \\
$t$ & time $[\mathrm{s}]$ \\
$T$ & temperature $[\mathrm{K}]$ \\
$t h$ & thickness $[\mathrm{m}]$ \\
$u$ & velocity [m/s] \\
$U$ & heat transfer coefficient $\left[\mathrm{W} /\left(\mathrm{m}^{2} \bullet \mathrm{K}\right)\right]$ \\
$V$ & volume $\left[\mathrm{m}^{3}\right]$ \\
$x$ & mass fraction \\
$\tilde{x}$ & mole fraction $[\mathrm{mol}]$ \\
$Y$ & absolute humidity $\left[\mathrm{kg}_{\mathrm{v}} / \mathrm{kg}_{\mathrm{da}}\right]$ \\
$z$ & compressibility factor \\
\hline & \\
\hline &
\end{tabular}

\section{Greek letters}

\section{$\rho$}

$\sigma$

$\Delta$

Subscripts

c

$e$

eff

$d a$

$g$

$i$

$l$

$m$

$\operatorname{mix}$

$n$ density $\left[\mathrm{kg} / \mathrm{m}^{3}\right]$

thermal conductivity $[\mathrm{W} /(\mathrm{m} \bullet \mathrm{K})]$

difference (delta)

condensate

external

effective

dry air

gas phase

interface, internal

liquid phase

metal

mixture

n-th component 


$\begin{array}{ll}s & \text { saturation } \\ t & \text { total } \\ v & \text { water vapor } \\ w & \text { water } \\ \infty & \text { infinite } \\ * & \text { corrected } \\ \text { Superscripts } & \\ c & \text { convective } \\ k & \text { conductive } \\ m & \text { parameter for eq. (20) } \\ 6 & \text { dry }\end{array}$

\section{INTRODUCTION}

The diffusion of small gas turbines for distributed power production led designers to study ways of increasing the efficiency and specific work of the recuperated Brayton cycle without increasing system complexity and related costs.

The Humid Air Turbine (HAT) technology [1] can greatly enhance gas turbine performance in terms of increased efficiency and specific work output. Compared to other mixed air/steam cycles, the HAT configuration introduces the "saturator" into the plant layout: this device carries out a direct contact exchange of heat and mass between two counter-flowing currents of liquid water and compressed air. In this framework a saturator for HAT cycles proved to be a relatively simple component for integration into a simple gas turbine [2][3][4].

A detailed and accurate modeling of the saturator is necessary for the complete understanding of both the component behavior and its integration into the whole gas turbine cycle. If the off-design performance modeling is useful for assessing the part-load performance of the plant, the transient analysis is very helpful for studying the dynamic behavior of the plant and for developing proper control systems [3] to follow the loads or to compensate for different ambient conditions.

The saturator on-design and off-design models have already been presented by Parente et al. in [5] and a first original transient model, TRANSAT 1.0, has been developed Cevasco et al. in [6]. The availability of new experimental data was the motivation for the review of the model, as described in this paper. Release 2.0 of TRANSAT model is now available not only for theoretical investigations but also for commercial design and analysis.

The TRANSAT 2.0 code has already been used for the design and the characterization of a direct contact heat exchanger for application in a zero emission power plant in the Veneto region (Italy). The thermodynamic characterization of a direct contact condenser for ENEL, the major Italian utility, in order to build a $\mathrm{H}_{2}$-fed combined cycle, with water recovery from the exhaust, was carried out experimentally and the TRANSAT 2.0 code was used to verify the accuracy of experimental data and to accomplish detailed performance analysis. The direct contact heat exchanger, derived from saturators technology, can be used as a condenser [7]of the steam contained in the gas flow at turbine outlet.

\section{TRANSAT 2.0 CODE OVERVIEW}

TRANSAT 1.0 was presented in [6]. 
The TRANSAT 2.0 code aims at transient and off-design analysis of saturators, humidification towers and direct contact heat exchangers equipped with structured packing.

Now TRANSAT 2.0 is entirely coded in C programming language and embedded in MATLAB/Simulink® environment; a Graphic User Interface simplifies data input and outputs analysis (Figure 1).

A full re-engineering of code architecture was carried out as a preliminary operation for the present work. The code has been translated from FORTRAN language to $C$ language allowing easier and more flexible integration in MATLAB environment. This recoding led to significant improvements of code computational performance without loss of accuracy. The simulation is now significantly faster than 1.0 with improved stability, allowing the reduction of the number of computation cells and increase of integration time step (e.g. on the same case study, the number of computation cells was decreased from 100 to 50 and the integration time step was increased from 0.01 to 0.1 ).

\section{SATURATOR TRANSIENT MODEL}

The transient model adopted in the TRANSAT 2.0 code is an evolution of the model employed in the steady-state SAT code [5].

Referring to the original set of 1-D equations used in the SAT code, an additional term for energy storage was introduced to account for the unsteadiness of the system. The system is considered to be adiabatic, thus no thermal loss is included in the model. The impact of this assumption is discussed in the paragraph about validation. The droplet size is assumed to be large enough to neglect the influence of surface tension. The radiation is neglected due to moderate temperatures.

The code is able to handle a wide range of gas species by setting the proper composition, 28 components are available to specify the mixture. The liquid phase can be only water. Considering the saturator discretization in $N$ cells, such as the one represented in Figure 2, the balance equations can now be written as follows:

\section{Enthalpy balance - Liquid side}

$$
m_{i, j+1} \cdot h_{i, j+1}-m_{i, j} \cdot h_{i, j}+d m_{\varepsilon} \cdot h_{i}\left(\bar{T}_{g}\right)-Z\left(d \dot{m} \mathbb{Z}_{i}+d m_{\varepsilon}\right) \cdot h_{i}\left(T_{i}\right)-U_{i}^{c} \cdot\left(\bar{T}_{i}-\bar{T}_{i}\right) \cdot a \cdot d z=\bar{c}_{i, i} \cdot M_{i, j} \cdot d T_{i, i} / \partial t
$$

\section{Enthalpy balance - Gas side}

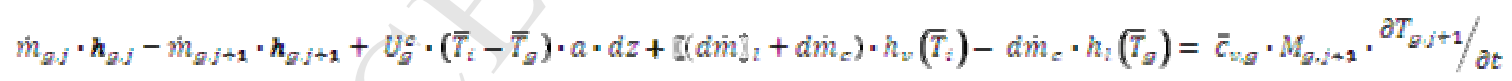

\section{Global enthalpy balance}

The global enthalpy balance in equation (3) can be obtained considering equation (4) that is equivalent to assume no thermal losses and no thermal capacitance at the interface.

$$
\begin{aligned}
& m_{l, j+1} \cdot \boldsymbol{h}_{l, j+1}-\bar{m}_{l, j} \cdot \boldsymbol{h}_{l, j}+m_{g, j} \cdot \boldsymbol{h}_{g, j}-m_{g, j+1} \cdot \boldsymbol{h}_{g, j+1}=\bar{c}_{v, l} \cdot M_{l, j} \cdot \partial T_{l, i} / \partial t+\bar{c}_{v, g} \cdot M_{q, j+1} \cdot \partial T_{g, j+1} / \partial t \\
& \left(U_{l}^{\sigma} \cdot\left(\bar{T}_{I}-\bar{T}_{i}\right)-U_{g}^{\sigma} \cdot\left(\bar{T}_{i}-\bar{T}_{g}\right)\right) \cdot a \cdot d z+\mathbb{Z}\left(d \bar{m}_{l}+d m_{\varepsilon}\right) \cdot\left(h_{I}\left(\bar{T}_{i}\right)-h_{v}\left(\bar{T}_{i}\right)\right)=0
\end{aligned}
$$


In the previous equations all the terms were evaluated at a generic time instant $n$. The subscripts $\mathrm{j}$ and $\mathrm{j}+1$ refer to the section where the respective term is being evaluated, while the symbol "-" indicates that the respective term is the mean cell value. The unsteady terms in the continuity and momentum equations were ignored.

The liquid and gas mass in equations (1-3) can be evaluated as follows:

$$
\begin{gathered}
M_{g, j+1}=V_{g} \cdot \bar{\rho}_{g}=d z=\frac{m_{g}+d \bar{m}_{l}+d m_{e}}{\bar{u}_{g, \text { eff }}} \\
M_{l, j}=V_{l} \cdot \bar{\rho}_{l}=d z=\frac{m_{l}}{\bar{u}_{l, \text { eff }}}
\end{gathered}
$$

The total liquid mass flow that evaporates across the cell is determined by:

$$
d m_{z}=d m_{l}+d m_{\varepsilon}=M_{w}=k_{x}=\ln \left(\frac{1-\overline{\tilde{x}}_{w, q}}{1-\overline{\tilde{x}}_{w, i}}\right) \cdot a \cdot d z
$$

The term $d m_{l}$ accounts for the actual liquid evaporation, while the term $d m_{c}$ accounts for droplet condensation whenever the gas temperature is below the corresponding vapor saturation temperature: it is assumed that the droplet condensate remixes with the liquid phase at the current gas temperature, otherwise this term is set to zero.

In the current model version, with respect to TRANSAT 1.0 implementation, the following assumption is made for the equations (1-10):

$$
T_{i}=T_{i}
$$

The interface temperature and the liquid temperature are supposed to be close and here they are assumed to be equal for simplicity, the same hypothesis was made in [3].

Introducing the specific heat in equations (1-2), and assuming $(n+1)$ as the reference instant, the previous relationships can be written as:

$$
\begin{aligned}
& -\left(\bar{m}_{l, j+i} \cdot \bar{c}_{p_{l} l}+d \bar{m}_{l} \cdot \bar{c}_{p, l i}\right) \cdot T_{l, j+1}^{n+1}+\left(\bar{m}_{l, j} \cdot \bar{c}_{p, l}-\bar{c}_{\mathrm{w}, l} \cdot M_{l, j} / \Delta t\right) \cdot T_{h, j}^{n+1}
\end{aligned}
$$

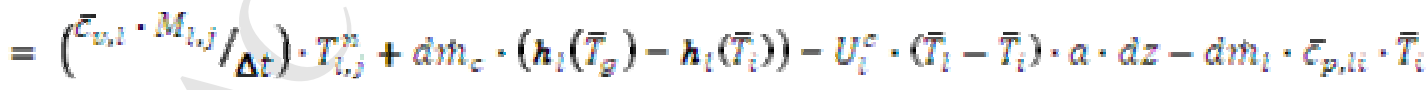

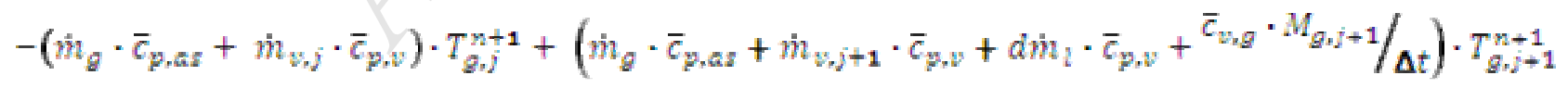

$$
\begin{aligned}
& =\left(\bar{\epsilon}_{v_{g} g} \cdot M_{g, j+1} / \Delta t\right) \cdot T_{g, j+1}^{n}+d h_{c} \cdot\left(h_{v}\left(\bar{T}_{i}\right)-h_{l}\left(\bar{T}_{g}\right)\right)-v_{g}^{c} \cdot\left(\bar{T}_{i}-\bar{T}_{g}\right) \cdot a \cdot d z-d h_{I} \cdot \bar{c}_{p_{k}, i i} \cdot \bar{T}_{i}
\end{aligned}
$$


In (9) and (10) it is assumed that all the mean values are calculated at the time instant $\mathrm{n}$. The terms $\bar{\epsilon}_{\mathrm{g}, k \mathrm{~s}}$ and $\bar{\epsilon}_{\mathrm{y}, v i \bar{i}}$ are the mean interface specific heat for the liquid and vapor phases, respectively, while the terms $\bar{c}_{\mathrm{p}, a s}$ and $\bar{\epsilon}_{\mathrm{p}, v}$ are the mean dry air and vapor specific heats.

Knowing the system properties at the instant $n$, the liquid and gas temperatures at the sections $j$ and $j+1$, for the instant $(n+1)$, can be determined with equations (9) and (10), respectively. The numerical solution scheme is thus implicit in the gas and water temperatures.

The water mass fraction can be written as:

$$
x_{W, j+1}=\frac{\frac{d m_{\bar{t}}}{m_{g}}+\frac{x_{w, j}}{1-x_{w_{i}}}}{1+\frac{d m_{t}}{m_{g}}+\frac{x_{w_{j}}}{1-x_{w, j}}}
$$

where $d m_{\varepsilon}$ can be determined using equation (7).

The maximum liquid mass flow that can evaporate is determined by (12):

$$
d m_{l}=\left[Y_{g}\left(T_{g, j+1}^{n}, p_{g, j+1}^{n}\right)-Y\left(T_{g, j}^{n}, p_{g, j}^{n}\right)\right]
$$

Knowing the liquid mass fraction at saturation conditions for section $(j+1)$ at the gas temperature ${ }^{T} g_{n j+1}$, it is possible to compare this with the value from (11). In the event that the actual vapor mass fraction is lower than the saturation value, $d m_{l}=d h_{z}$ and $d m_{c}=0$. Otherwise part of the evaporated water will re-condense: $d m_{e}$ can be determined with (7), considering the saturation condition at the cell outlet.

The heat and mass transfer coefficient are evaluated for each cell using the Bravo, Rocha and Fair correlations for structured packing [8] and Ackerman's factor is used [5][9].

In the TRANSAT model the thermal capacity of the packing and the pipes metal is not considered, this is a relevant simplification for the transient behavior analysis. In this respect, when time-dependant behavior of the specific case is largely dominated by packing and/or vessel thermal capacitance, the numerical scheme can be regarded as a "time marching" solution towards steady-state.

Two humid air models are available: Hyland \& Wexler model [10][11] and Mollier model (see [5], paragraph 3).

\section{MOSAT TEST RIG LAYOUT}

The purpose of "MOSAT project" [12] was to build a test rig able to collect a wide set of experimental data.

The plant was built using off-the-shelf components, except for the modular saturation tower vessel. The core of the rig consists of the saturation tower. Structured internal packing, Figure 3, is used because it is attractive for power generation plants due to the relatively small pressure drop along the saturator axis (which applies to the air in a gas turbine cycle moving from the compressor to the expander). In this way the internal geometry, which is relevant to the design phase of the tower and to the validation of simulation models, is precisely parameterized. 
The test tower is composed of four flanged pipes, and top and bottom structures. A maximum of 8 packing modules, each of 200 mm length and $80 \mathrm{~mm}$ diameter, can be placed within the tower.

The top of the saturator contains the water injectors and the outlet pipe for humid air.

The experiments were carried out using water and atmospheric air. A brief discussion on the uncertainty of the experimental results is given in Appendix A.

\section{VALIDATION}

The validation of TRANSAT 2.0 code using the Simulink environment proved the stability and accuracy of the model according to the underlying hypothesis.

Regarding the large set of experimental data produced by the MOSAT test campaign [12] the validation carried out considered just a selected sample of test cases, reported in Table 1.

Six calculations with different boundary conditions were carried out in order to cover a wide operating field.

Each test case is characterized by a set of input parameters:

- Gas inlet temperature $\left({ }^{T_{g_{i n}}}\right)$

- Liquid water inlet temperature $\left(T_{l_{\text {in }}}\right)$

- Operating pressure of the vessel (p)

- Gas mass flow rate $\left(m_{g_{\text {in }}}\right)$

- Liquid water mass flow rate $\left({ }^{n} l_{l_{m}}\right)$

An important control parameter is the Liquid to Gas Ratio (13):

$$
L_{G}=\frac{m_{l_{\mathrm{in}}}}{m_{g_{\mathrm{m}}}}
$$

such a parameter dominates the thermodynamic evolution in the saturation tower: when L/G increases, the gas outlet absolute humidity increases. However, for high values of packing height the effect is less significant.

The monitored parameters for data analysis and post processing are:

- Gas outlet temperature $\left(T_{g_{\text {out }}}\right)$

- Liquid water outlet temperature $\left({ }^{T_{l_{\mathrm{Da}}}}\right)$

- Outlet gas mass flow rate $\left({ }^{n} g_{\text {out }}\right)$

- Outlet liquid water mass flow rate $\left({ }^{m} l_{\text {out }}\right)$

- Evaporated water mass flow $\left(d m_{t}\right)$

To check the model theoretical validity, a steady state enthalpy balance is considered (14): 


$$
\mathbb{Z}\left(m_{\beth_{l}}+d \dot{m}_{l}\right) \cdot\left(h_{l}+d h_{l}\right)+m_{g}^{R} \cdot h_{g}^{r}=m_{l} \cdot h_{l}+m_{g}^{r} \cdot\left(h_{g}^{r}+d h_{g}^{r}\right)
$$

Eq. 13 can show macroscopic errors in model theory or settings. The error weighted over the gas enthalpy drop is a convenient parameter to estimate the accuracy of the overall enthalpy balance.

In order to handle mass flows in the order of $0.1 \mathrm{~g} / \mathrm{s}$ a geometric similitude was used. The effective contact area per unit of mass flow rate was not changed but the gas and water mass flow rates were increased by a factor of 10 . The flow velocity was maintained equal to the actual velocity corresponding to the actual mass flow: so an increased diameter was introduced following the relation in equation (15).

$$
d_{\text {reduced }}^{2}=d_{\text {actual }}^{2} \cdot \frac{m_{\text {reducta }}}{m_{\text {actual }}}
$$

where reduced indicates the corrected inputs introduced in the code and actual indicates the real inputs from Table 1.

Table 1 shows the experimental data from the MOSAT project used as input values for TRANSAT 2.0 steady state validation.

In Table 2 the output results obtained from TRANSAT 2.0 simulations are reported.

In Table 3 the absolute differences between experimental data and simulated results are shown. In general, it can be observed that the gas outlet temperature is accurately predicted, whereas the outlet water temperature and the evaporated water show substantial absolute error. Such discrepancies are further discussed below.

The temperature gap between MOSAT and TRANSAT 2.0 is due both to thermal loss from the saturator system to external environment and to the over-saturation of the output gas stream [13].

\section{a) Thermal Loss}

The saturation tower heat loss comes primarily from two sources:

(i) four coupling flanges, not insulated, Figure 4

(ii) insulation shell around the tower, Figure 4

These heat losses were estimated to evaluate the possibility to integrate such estimation directly into the code.

To model these losses, we assumed a radial conduction through the tower wall and free-convection from the external bound of the wall to surrounding area. The following equations were used:

$$
\text { Qut }_{\text {flange }}=\frac{\bar{T}-T_{\infty}}{R_{\varepsilon}}
$$

where $\bar{T}$ is the mean temperature in the tower and it is equal to

$$
\bar{T}=\sum_{n=1}^{4} \frac{T_{g_{n}}+T_{l_{n}}}{2} / 4
$$


in which $L$ is the total thickness of the 4 flanges along tower longitudinal axis and $\sigma$ is the conductivity of the steel of the flanges.

$$
R=\frac{1}{A_{e} \cdot h_{i}^{e}}+\frac{1}{A_{i} \cdot h_{i}^{e}}
$$

where the $T_{n}$ are the temperatures measured along the saturator axis, excluding tower ends, see Figure 4.

The total resistance, see Figure $5, R_{t}$ is considered as a series of conductive $(k)$ and convective $(c)$ contributions:

$$
R_{z}=\mathbb{R}^{k}+\mathbb{R}^{e}
$$

$R^{k / \operatorname{lange}}=\frac{1}{2 \pi \cdot L \cdot \sigma} \cdot \ln \frac{\mathrm{r}_{\text {external }}}{\mathrm{r}_{\text {internal }}}$

In (19) $A$ is the total exchange area, $\boldsymbol{h}_{i}^{\mathcal{E}}$ is the internal convective coefficient and $\boldsymbol{h}_{\Xi}^{\mathcal{E}}$ is the external convective coefficient.

A gross estimation of the internal radial convective heat transfer was conducted, although the evaluation of the heat transfer coefficient is very difficult due to the complex characteristics of the fluid (two phase, change of state). The correlations presented in [8] were used. Considering the humid air phase only, the $h^{c}$ varied, depending on the flow characteristics, from 4 to $7 \mathrm{~W} /\left(\mathrm{m}^{2} \mathrm{~K}\right)$; for the liquid phase only $h^{c}$ varied from 65 to $100 \mathrm{~W} /\left(\mathrm{m}^{2} \mathrm{~K}\right)$. On top of that it is reasonable to consider that a liquid film covers the whole internal surface of the pipe, hence the heat exchange towards the pipe is driven by the liquid phase according to its heat transfer coefficient. The mass transfer between liquid and gas phase balances the heat transferred by the liquid to the pipe. In conclusion, the convective coefficient inside the pipe is assumed to be equal to the liquid convective coefficient.

Regarding the thermal resistance of the insulation shell, the approach is the same as for the flanges.

Table 4 reports the coefficients used for estimation of heat losses: the $\boldsymbol{h}_{e}^{e}$ coefficient is calculated by the simplified dimensional equation (21) proposed by [8] for natural convection.

$$
h=b \cdot(\Delta T)^{m} \cdot L^{3 m-1}
$$

where $m$ and $b$ are chosen as 0.25 and 1.37 respectively.

The thermal fluxes calculated with (16) are subtracted from the water thermal flow at the exit in order to estimate the impact caused by heat losses on such a measurable parameter, see equations (22) and (23).

$$
\begin{gathered}
\Delta T_{\text {flargel }}=\frac{q_{\text {out }}^{\text {flanges }}}{c_{p . l} \cdot m_{l}} \\
\Delta T_{\text {insulation }}=\frac{q_{\text {out }} \text { insulation }}{c_{p l l} \cdot m_{l}}
\end{gathered}
$$

$c_{p, l}$ is the constant pressure specific heat of the liquid current at the outlet conditions.

\section{b) Over- saturation}


MOSAT project has shown a systematic over-saturation of the outlet gas stream, the absolute humidity of the air at tower top being of the order of $10 \%$ greater than the saturation limit [13]. This observation is confirmed by comparison between theoretical saturation and experimental data (Table 3).

For the estimation of the impact of the over-saturation, in terms of outlet water temperature, the following equations were used:

$$
\begin{aligned}
& q_{o s}=\left[h_{l}\left(T_{l_{\text {Qut }}}\right)-h_{v}\left(p_{v_{\text {sut }}}\right)\right] \cdot \Delta d m_{l} \\
& \Delta d m_{l}=d m_{L_{\text {MaSAT }}}=d m_{l_{\text {TRANSAT }}} \\
& \Delta T_{o z}=\frac{q_{o r}}{\epsilon_{p l} \cdot m_{l_{\text {qut }}}}
\end{aligned}
$$

The $\Delta T$ calculated with equations (21), (22) and (26) are shown in Table 5, where $T^{*}$ corresponds to:

$$
T^{*}=T_{l_{\text {out }} \text { Transat }}+\Delta T_{\text {flanges }}+\Delta T_{\text {ingulation }}+\Delta T_{\text {og }}
$$

It is straightforward to see that the total thermal losses caused by conductive and convective heat transmission and the presence of a systematic over-saturation are sufficient to explain and justify the differences between simulated and experimental water outlet temperature. In conclusion, from Table 5, it can be observed that the maximum error on water outlet temperature estimation made by TRANSAT 2.0 code is lower than $1.25 \%$ in absolute value.

Figure 6 shows the reduction of the water outlet temperature difference between calculated and experimental data switching from raw TRANSAT output values to $\mathrm{T}^{*}$ corrected values.

Figure 7 shows the comparison between MOSAT and TRANSAT 2.0 on the water and gas temperatures evolution versus the nondimensional height of the saturator for the test case number 4. In the secondary y axis the evolution of the gas stream relative humidity is reported. It is easy to notice that the air saturation is completed at about the $25 \%$ of the tower height and the largest part of the heat transfer is accomplished in the same fraction of the saturator.

\section{TRANSIENT ANALYSIS FEATURES}

Even though the code has been validated only in steady- state conditions, TRANSAT 2.0 retains transient analysis capability. In this respect improved numerical stability was reached due to a better estimation of gas and water mass in the elementary cells and a more accurate updating of molar compositions of the air stream across following iterations.

A significant example of improved stability is the analysis of the time response of the model forced by a double step input variation. The startup time is ignored.

Figure 8 shows the comparison between two simulations performed with TRANSAT 1.0 (left) and TRANSAT 2.0 (right).

In order to investigate the saturator response to small system disturbances, the water inlet temperature was changed through a sequence of two steps: starting from a stable regime, first a $+5 \%$ variation was done, and then, after new stable regime attained, a second step change of $-10 \%$. 
The difference between the two behaviours is very clear: TRANSAT 1.0 shows instability in the output gas temperature, within the time range where the double step is imposed, while TRANSAT 2.0 now shows a stable trend.

\section{CONCLUSIONS AND PERSPECTIVES}

The upgrade and validation efforts towards the TRANSAT release 2.0 allow the following conclusions to be drawn:

a) This latest release of TRANSAT is able to simulate saturator on-design and off-design conditions with good accuracy on all the significant parameters except the water outlet temperature and the evaporated water;

b) Including thermal loss estimation the error on water temperature is less than $1 \%$ (MOSAT standard deviation $\sigma=2.832 \mathrm{~K}$ [13]);

c) The error of about $10 \%$ on water evaporated is in agreement with MOSAT project conclusions, as it showed consistently an average $10 \%$ over-saturated gas flow at the saturator exit;

d) Enhanced numerical stability was achieved;

e) The computational speed is largely increased thanks to reduced number of elementary cells and increased integration time step;

f) In all the presented test cases for validation the gas outlet stream was in saturation condition;

g) The validation needs to be carried out also in transient conditions, but additional experimental data are required;

h) A code-embedded conductive and convective thermal losses estimation needs to be implemented;

i) TRANSAT 2.0 is ready to be used as a steady-state design tool for pressurized saturation towers.

\section{REFERENCES}

[1] M. Jonsson, J. Yan, 2005, "Humidified gas turbines - a review of proposed and implemented cycles", Energy 30 (2005) 10131078.

[2] T. Lindquist, M. Thern, T. Torisson, 2002, "Experimental and Theoretical Results of a Humidification Tower in an Evaporative Gas Turbine Cycle Power Plant”, ASME Paper 2002-GT-30127.

[3] H. Araki, Y. Katagiri, S. Marushima, S. Hatamiya, S. Higuchi, M. Tsukamoto, 2007, "Experimental Results of Humidification and Water Recovery of The Advanced Humid Air Turbine System Pilot Plant”, IGTC 2007, TS-012.

[4] Per M. Rosén, 2000, "Evaporative Cycles- in Theory and in Practice", Doctoral Thesis, Lund Institute of Technology, Lund, Sweden.

[5] J. Parente, A. Traverso, A. F. Massardo, 2003, "Saturator Analysis for an Evaporative Gas Turbine Cycle”, Applied Thermal Engineering, Elsevier Science, 23, 1275-1293.

[6] R. Cevasco, J. Parente, A. Traverso, A.F. Massardo, 2004, "Off-Design and Transient Analysis of Saturators for Humid Air Turbine Cycles", ASME paper GT-2004-53315.

[7] D. Bharathan, E. Hoo, P. D'Errico, 1992, Assessment of the Use of Direct Contact Condensers with Wet Cooling Systems for Utility Steam Power Plants. 38 pp.; NICH Report No. TP-254-4514. Available at http://www.osti.gov/energycitations/servlets/purl/10124218-DGQNbd/

[8] Perry's Chemical Engineer's Handbook (Perry R. H., Green D. - editors), 1997, 7th edition, McGraw-Hill, New York. 
[9] J. Parente, A. Traverso, A. Massardo, 2003, "Micro Humid Air Cycle Part A: Thermodynamic and Technical Aspects", ASME paper GT-2003-38326.

[10]Hyland R.W., Wexler A., 1983, "Formulations for the Thermodynamic Properties of Dry Air from 173.15 to 473.15 K, and of Saturated Moist Air from 173.15 K to 372.15 K, at Pressures to 5 MPa”, ASHRAE Transactions, 89 No 2A, pp. 520-535.

[11]Hyland R.W., Wexler A., 1983, "Formulations for the Thermodynamic Properties of the Saturated Phases of H2O from 173.15 K to 473.15 K”, ASHRAE Transactions, 89 No 2A, pp.500-519.

[12]A.A. Pedemonte, A. Traverso, A.F. Massardo, 2008, "Experimental analysis of pressurised humidification tower for humid air gas turbine cycles. Part A: Experimental campaign”, Applied Thermal Engineering, Elsevier Science, Vol. 28, 1711-1725.

[13]A.A. Pedemonte, A. Traverso , A.F. Massardo, 2008, "Experimental analysis of pressurised humidification tower for humid air gas turbine cycles. Part B: Correlation of experimental data”, Applied Thermal Engineering, Elsevier Science, Vol. 28, 1623-1629. [14]A. Traverso, A. F. Massardo, 2002, "Thermoeconomic Analysis of Mixed Gas-Steam Cycles”, Applied Thermal Engineering, Elsevier Science, 22, 1-21.

\section{APPENDIX A: UNCERTAINTY OF EXPERIMENTAL DATA}

\section{Temperature and pressure}

All thermocouples installed to monitor the tower body and to control the inlet temperatures are "K" type class 1 . Such thermocouples provide Type A uncertainty errors of $\pm 1.5^{\circ} \mathrm{C}$ over the range $-40^{\circ} \mathrm{C}-1000^{\circ} \mathrm{C}$.

For ease of construction the inlet air temperature is measured as close as possible to the saturator body. A few centimeters gap between the point of measure and the saturator remained, thus leading to a displacement error in the inlet temperature. Such an error was estimated as being less than $2^{\circ} \mathrm{C}$, which was considered acceptable.

Piezoresistive absolute and differential pressure transducers were used providing Type A uncertainty of $\pm 2 \%$ from $0{ }^{\circ} \mathrm{C}$ to $50^{\circ} \mathrm{C}$ and $\pm 4 \%$ from $-20^{\circ} \mathrm{C}$ to $80^{\circ} \mathrm{C}$.

\section{Outlet air humidity - Water consumption measurement}

One of the most challenging problems of saturation towers is the accurate measurement of humidity of the air at the tower outlet. In fact, the difference in water mass flow between inlet and outlet may be small enough to severely affect the precision of the resulting consumption (each water flow meter comes with an error of $\pm 1 \%$, thus the error in water consumption may be in excess of $\pm 30 \%$, depending on the operating conditions). According to the procedure employed in [2], it was decided not to use the in-line water flow measurements. Water consumption was estimated by averaging over a certain period of time the feed water which had to be supplied to the system in order to restore the level to the bottom of the tower. In fact, the approach consists in estimating the time that a known amount of water takes to flow out of the saturator with the humid air, while the operating regime of the saturator remains unchanged. This system provides a value that is a mean over a time period, but it improves measurement accuracy. The on-line water flow measurements were employed to only to estimate the $\mathrm{L} / \mathrm{G}$ ratio, i.e. the ratio between the water mass flow and dry air mass flow at saturator inlets (top and bottom, respectively), which is an important operating parameter for the saturator.

Since the outlet humidity was measured by calculating the time for the saturator to consume a certain amount of water, the resulting precision was relatively high, being about $\pm 0.5 \%$. 


\section{LIST OF FIGURES AND TABLES}

Figure 1- TRANSAT 2.0 main interface mass

Figure 2 - Saturator elementary cell

Figure 3 - Structured internal packing

Figure 4 - Two modules of MOSAT saturation tower: 1.insulated pipe, 2.thermocouples, 3.uninsulated flanges

Figure 5- Series of thermal resistances for the evaluation of heat losses

Figure 6 - Reduction of Liquid Temperature error

Figure 7 - Gas relative Humidity and Temperatures evolution vs tower height (MOSAT-TRANSAT comparison)

Figure 8 - Comparison between TRANSAT 1.0 (left) and TRANSAT 2.0 (right): response to double step (+5\%, -10\%) of inlet water temperature

Table 1 - Experimental input data for TRANSAT 2.0 validation

Table 2 - Comparison between MOSAT data and TRANSAT 2.0 output results

Table 3 -MOSAT - TRANSAT 2.0 absolute differences

Table 4 - Values used for estimation of thermal loss

Table 5 - Comparison between MOSAT and TRANSAT 2.0 water outlet temperature including thermal losses 
- TRANSAT is able to simulate saturator behavior with good accuracy;

- Including thermal loss estimation the error on water temperature is less than $1 \%$;

- Enhanced numerical stability was achieved;

- The computational speed is largely increased without loss of accuracy;

- TRANSAT 2.0 is ready to be used as a design tool for pressurized saturation towers. 
Saturator

Transient Model SATRANS 2.0

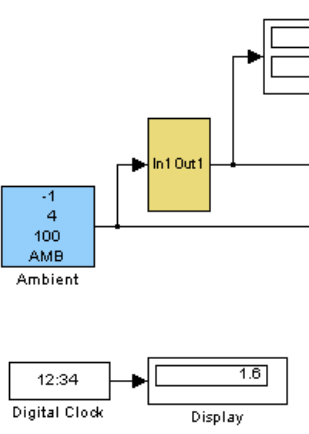

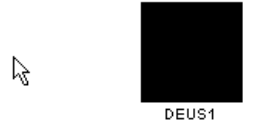

$+\frac{1}{\mathrm{e}+005}$
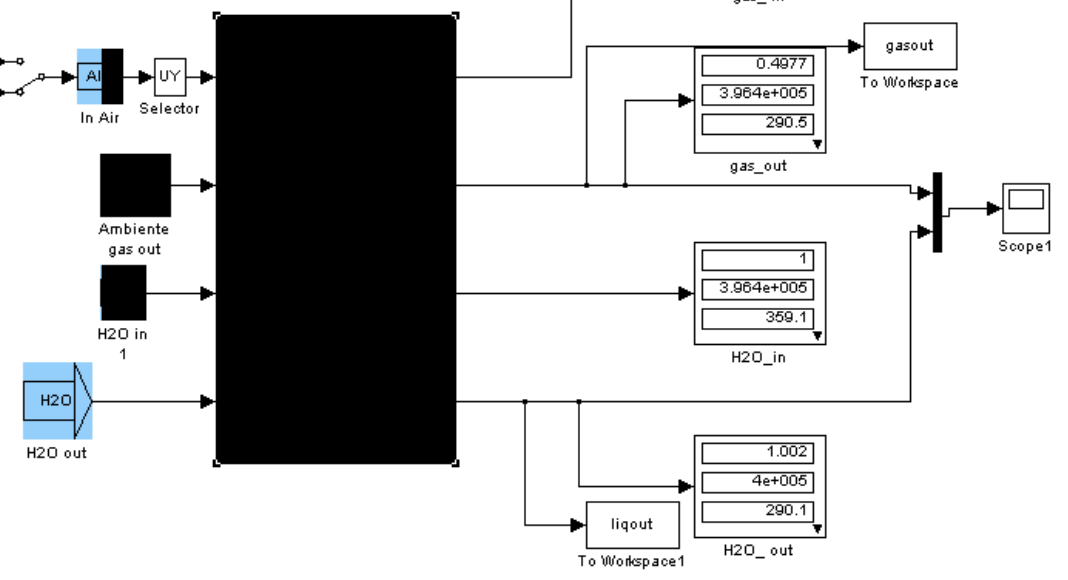


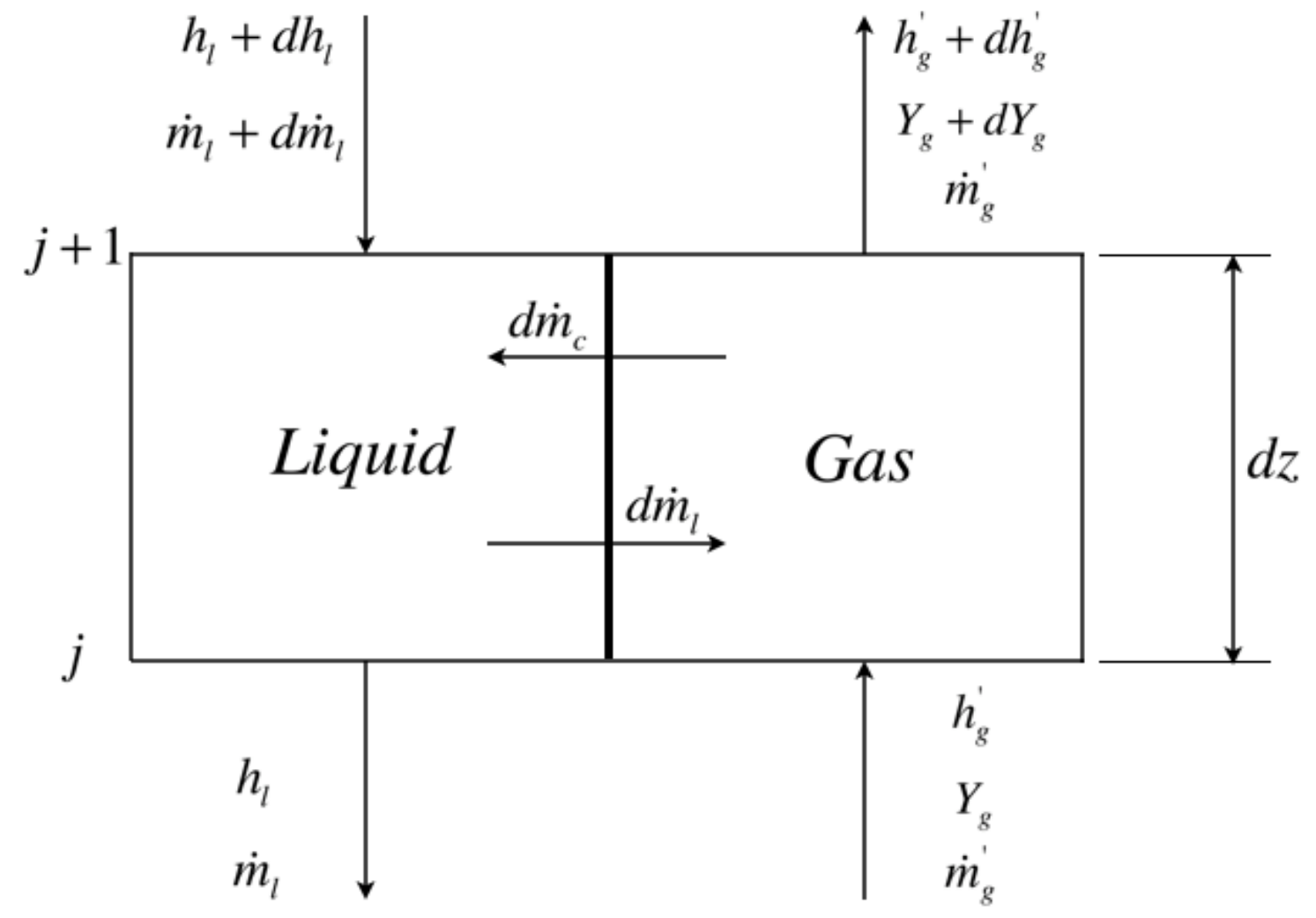




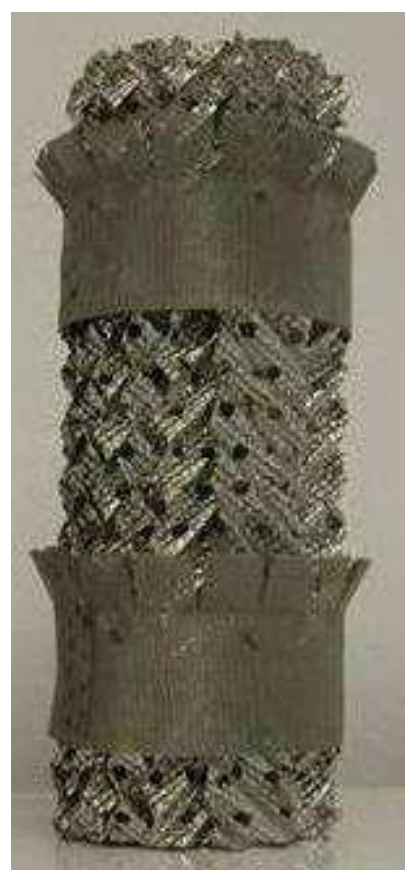




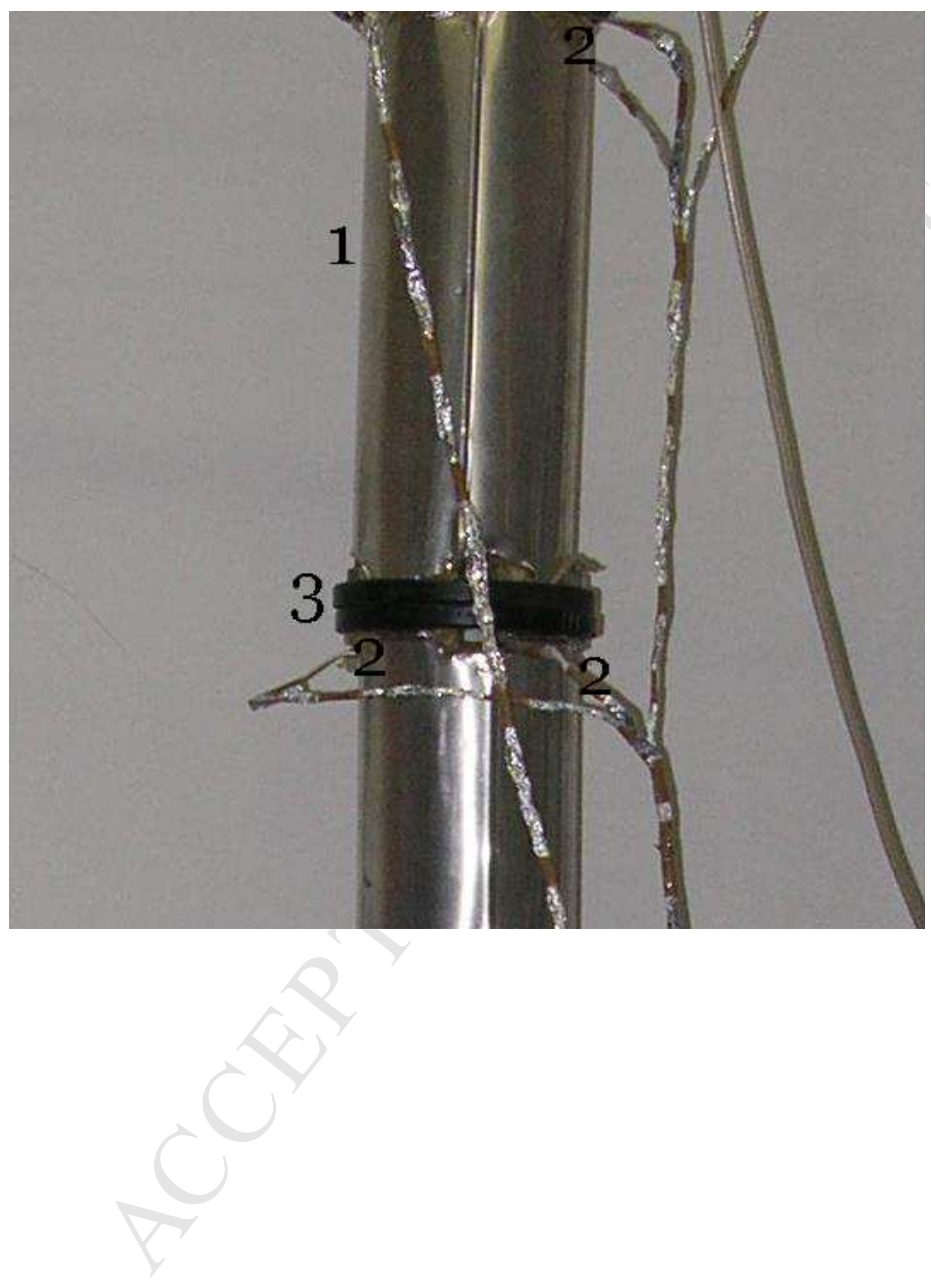




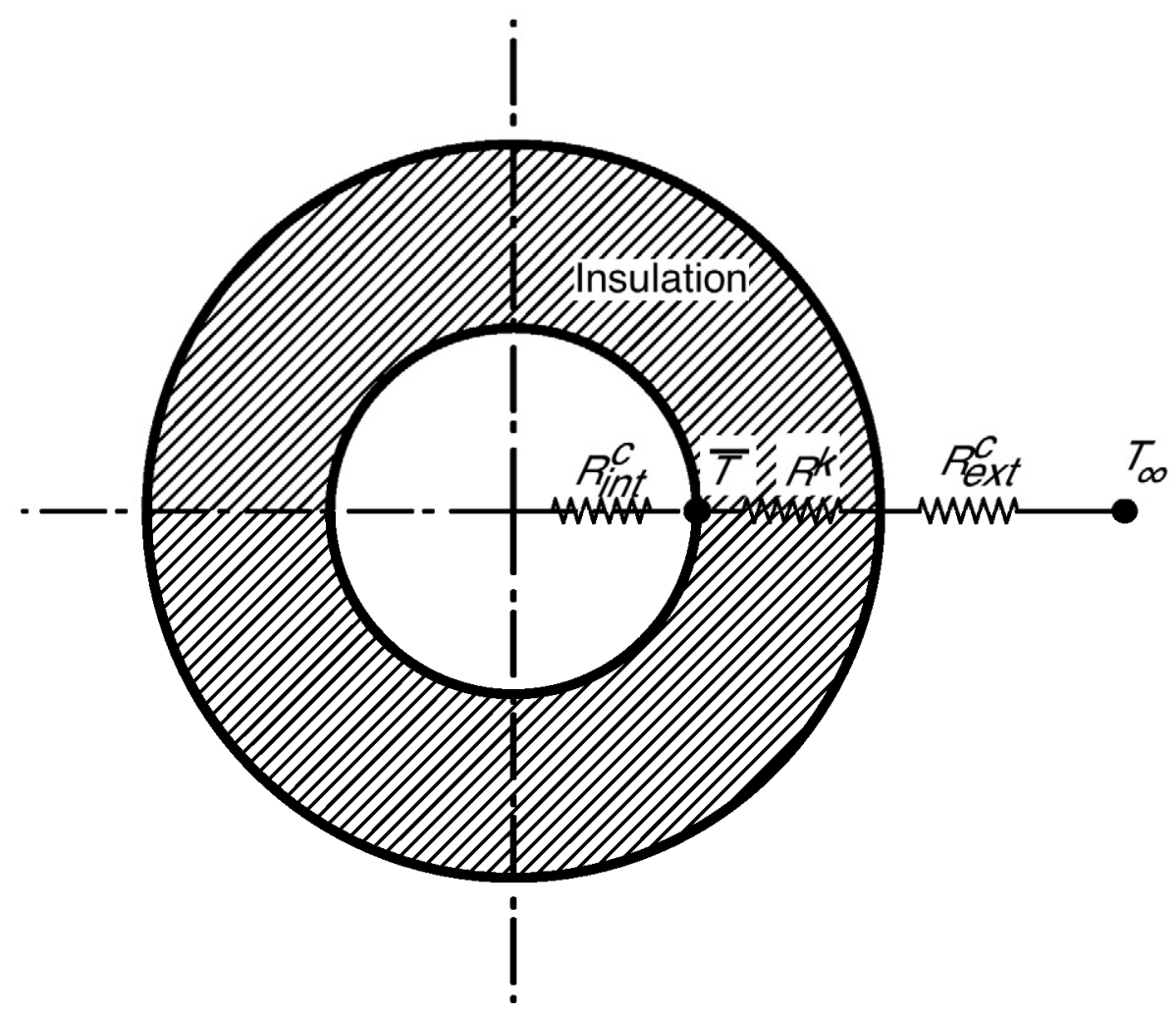




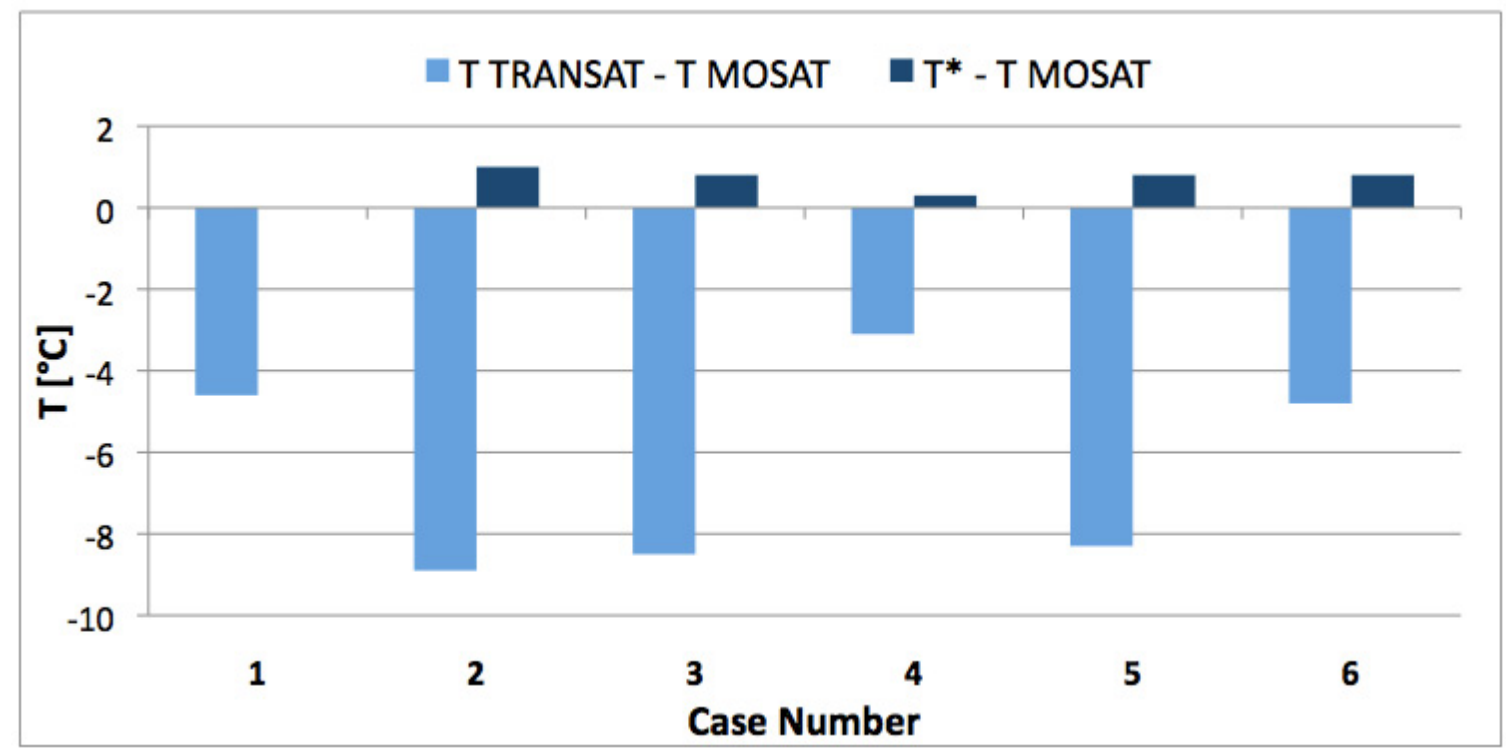




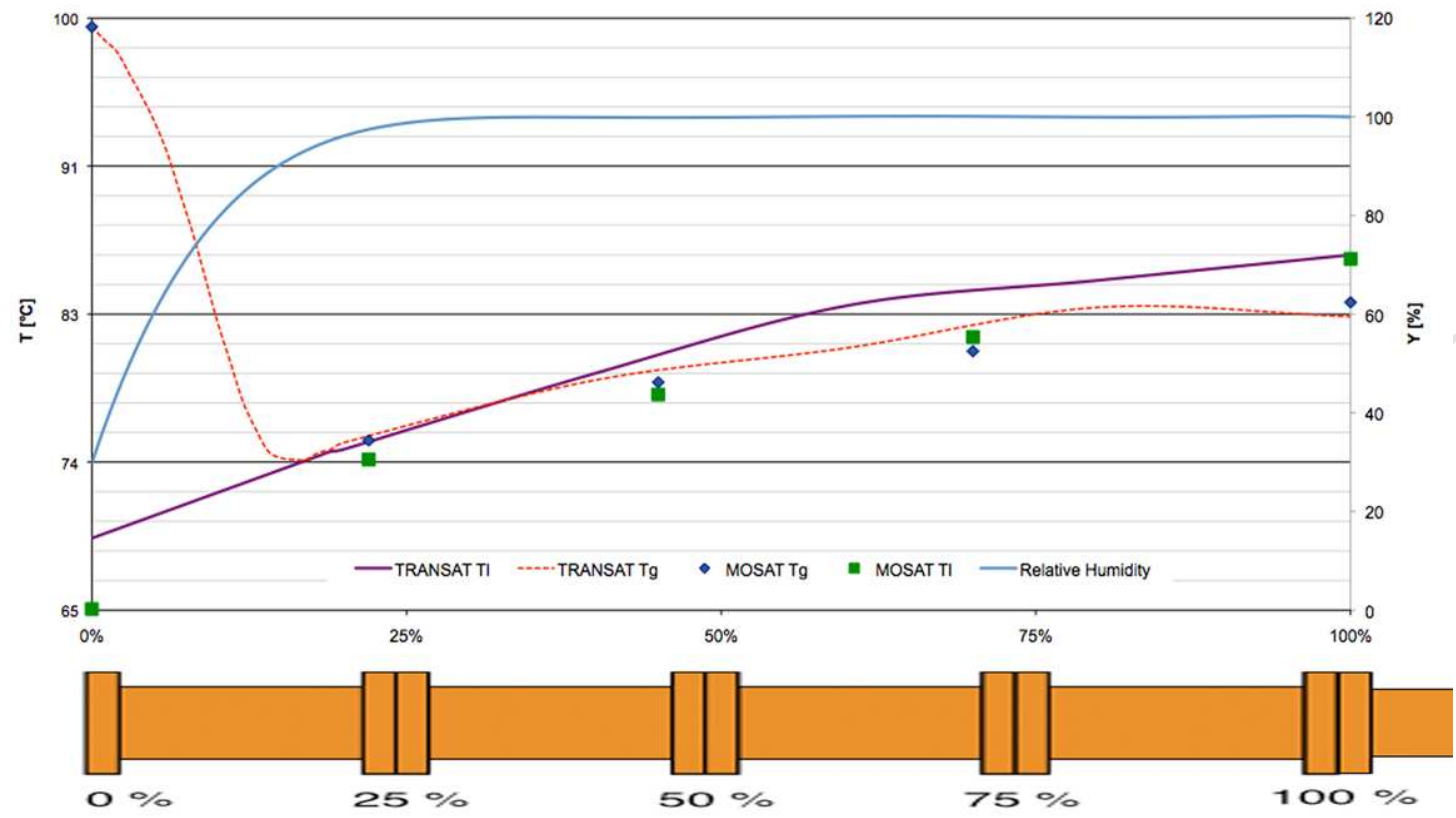




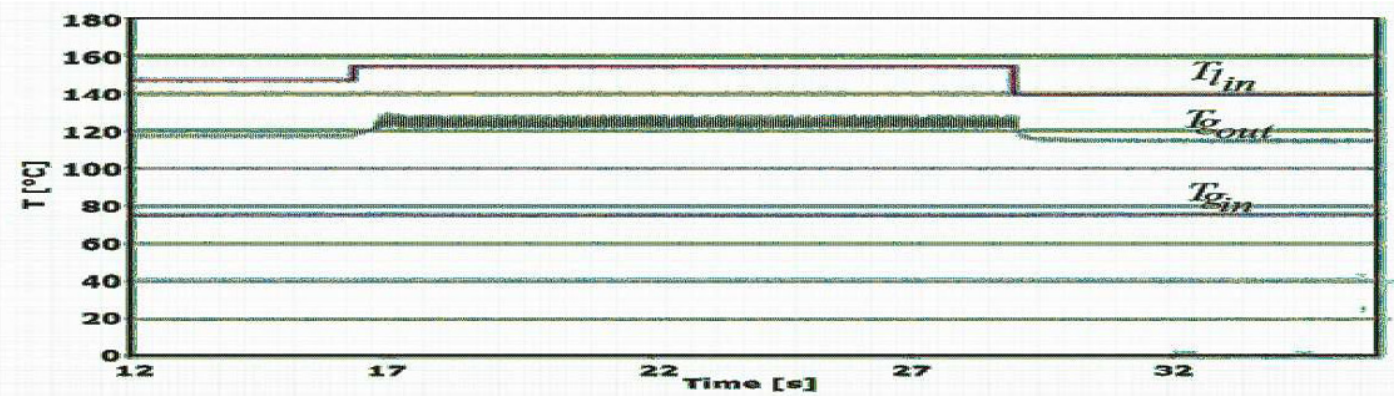




\begin{tabular}{ccccccc}
\hline test $^{\circ}$ & $\mathrm{p}(\mathrm{bar})$ & $\mathrm{T}_{\text {gin }}\left({ }^{\circ} \mathrm{C}\right)$ & $\mathrm{T}_{\text {lin }}\left({ }^{\circ} \mathrm{C}\right)$ & $\mathrm{m}_{\text {gin }}(\mathrm{g} / \mathrm{s})$ & $\mathrm{m}_{\text {lin }}(\mathrm{g} / \mathrm{s})$ & $\mathrm{L} / \mathrm{G}$ \\
\hline 1 & 3 & 101 & 76 & 10 & 10 & 1 \\
2 & 4 & 300 & 129 & 10 & 10 & 1 \\
3 & 4 & 200 & 129 & 10 & 10 & 1 \\
4 & 4 & 100 & 86 & 5 & 10 & 2 \\
5 & 4 & 200 & 86 & 10 & 5 & 0.5 \\
6 & 5 & 200 & 135 & 10 & 10 & 1
\end{tabular}




\begin{tabular}{|l|l|l|l|l|l|l|}
\hline \multicolumn{3}{|c|}{ MOSAT } & \multicolumn{4}{|l|}{ TRANSAT 2.0 } \\
\hline $\mathrm{n}^{\circ}$ & $\mathrm{T}_{\mathrm{g}}$ out & $\mathrm{T}_{1}$ out & $\mathrm{dm}_{l}(\mathrm{~g} / \mathrm{s})$ & $\mathrm{T}_{\mathrm{g}}$ out & $\mathrm{T}_{1}$ out & $\mathrm{dm}_{l}(\mathrm{~g} / \mathrm{s})$ \\
& & & & & & \\
\hline 1 & 64.0 & 46.4 & 0.62 & 63.9 & 51.0 & 0.58 \\
\hline 2 & 92.9 & 79.6 & 1.85 & 92.8 & 88.5 & 1.67 \\
\hline 3 & 92.6 & 68.6 & 1.99 & 92.0 & 77.1 & 1.80 \\
\hline 4 & 83.2 & 65.0 & 0.50 & 82.3 & 68.1 & 0.46 \\
\hline 5 & 76.9 & 68.2 & 0.86 & 76.6 & 76.3 & 0.78 \\
\hline 6 & 99.7 & 73.2 & 2.09 & 99.5 & 78.0 & 1.90 \\
\hline
\end{tabular}




\begin{tabular}{|l|l|l|l|l|}
\hline \multicolumn{5}{|l}{ MOSAT - TRANSAT 2.0} \\
\hline $\mathrm{n}^{\circ}$ & $\Delta \mathrm{T}_{\mathrm{g}}$ out & $\Delta \mathrm{T}_{1}$ out & $\mathrm{dm}_{1}$ & \% error $\mathrm{dm}_{1}$ \\
\hline 1 & 0.2 & -4.6 & 0.04 & $6.5 \%$ \\
\hline 2 & 0.1 & -8.9 & 0.18 & $9.7 \%$ \\
\hline 3 & 0.6 & -8.5 & 0.19 & $9.7 \%$ \\
\hline 4 & 0.8 & -3.1 & 0.04 & $8.4 \%$ \\
\hline 5 & 0.2 & -8.3 & 0.08 & $9.1 \%$ \\
\hline 6 & 0.1 & -4.8 & 0.19 & $9.1 \%$ \\
& & & & \\
& & & & \\
& & & & \\
\end{tabular}




\begin{tabular}{|l|l|l|}
\hline & Flanges & Insulation \\
\hline $\mathbf{T} \infty$ & 25 & 25 \\
\hline $\mathbf{r}$ internal & $0.04 \mathrm{~m}$ & $0.04 \mathrm{~m}$ \\
\hline $\mathbf{r}$ external & $0.12 \mathrm{~m}$ & $0.10 \mathrm{~m}$ \\
\hline $\mathbf{L}$ & $0.12 \mathrm{~m}$ & $1.48 \mathrm{~m}$ \\
\hline $\mathbf{k}$ & $10 \mathrm{~W} / \mathrm{m} \cdot \mathrm{K}$ & $0.2 \mathrm{~W} / \mathrm{m} \cdot \mathrm{K}$ \\
\hline $\mathbf{h}_{\mathbf{e}}$ & $4-6 \mathrm{~W} / \mathrm{m}^{2} \mathrm{~K}$ & $4-6 \mathrm{~W} / \mathrm{m}^{2} \mathrm{~K}$ \\
\hline $\mathbf{h}_{\mathbf{i}}$ & $65-100 \mathrm{~W} / \mathrm{m}^{2} \mathrm{~K}$ & $65-100 \mathrm{~W} / \mathrm{m}^{2} \mathrm{~K}$ \\
\hline
\end{tabular}




\begin{tabular}{|l|l|l|l|l|l|l|l|}
\hline $\mathrm{n}^{\circ}$ & $\Delta \mathrm{T}_{\text {Flanges }}$ & $\Delta \mathrm{T}_{\text {Ins }}$ & $\Delta \mathrm{T}_{\text {os }}$ & $\Delta \mathrm{T}_{\text {total }}$ & $\mathrm{T}_{1}^{*}$ & $\begin{array}{l}\text { error } \\
\text { on } \mathrm{T} 1 \\
{\left[{ }^{\circ} \mathrm{C}\right]}\end{array}$ & $\begin{array}{l}\text { enthalpy } \\
\text { balance } \\
\%\end{array}$ \\
\hline 1 & 2.9 & 0.5 & 1.2 & 4.6 & 46.4 & 0.0 & 0.32 \\
\hline 2 & 5.1 & 0.9 & 1.9 & 7.9 & 80.6 & 1.0 & 0.21 \\
\hline 3 & 4.9 & 1.0 & 1.8 & 7.8 & 69.2 & 0.8 & 0.37 \\
\hline 4 & 1.5 & 0.4 & 1.0 & 2.8 & 65.2 & 0.3 & 0.26 \\
\hline 5 & 4.8 & 0.9 & 1.8 & 7.6 & 68.7 & 0.8 & 0.05 \\
\hline 6 & 2.3 & 0.1 & 1.6 & 4.0 & 74.0 & 0.8 & 0.12 \\
& & & & & & & \\
& & & & & & & \\
\end{tabular}

